\title{
Peculiarities of deforming a rectangular edge welded envelope made of commercial titanium alloy
}

\author{
O.P. Tulupova ${ }^{1, \dagger}$, A.A. Slesareva ${ }^{1}$, A.A. Kruglov ${ }^{2}$, F.U. Enikeev ${ }^{1}$ \\ †box_mail_2011@mail.ru
}

\author{
${ }^{1}$ Ufa State University of Oil \& Petroleum, Kosmonavtov, 1, 450062 Ufa, Russia \\ ${ }^{2}$ Institute for Metals Superplasticity Problems, Khalturina, 39, 450001 Ufa, Russia
}

\begin{abstract}
Superplastic forming of the rectangular edge welded envelope consisting of two rectangular sheets welded along their periphery is considered. The diameter of the cylindrical shell manufactured turns out to be considerably less as compared with the initial width of the rectangular edge welded envelope to be formed superplastically. The deforming of the envelope is effected in a free state, i.e. without fixing the edges of the envelope. Finite element analysis of the stress state is effected by using ANSYS software. Time dependencies of the dome height and width of the envelope are obtained for two cases: plane strain state and plane stress state. The following three stages of the deforming process have been established. Elastic bending of the envelope takes place at the first stage, when the dome height is sharply increasing while the width of the envelope is considerably diminishing. Second stage corresponds to the stationary superplastic flow when the dome height and width of the envelope are changing not so much. The third stage is characterizing by increasing the width of the envelope with the increase in the dome height up to its maximum value. The commercial titanium alloy VT14 (Ti-4,2Al-2,7Mo-1,2V) is used in experiments. The comparison of the analytical predictions with corresponding finite element solutions as well as with experimental data is made.
\end{abstract}

Keywords: superplastic forming, edge welded envelope, finite element modeling, ANSYS.

Superplastic forming is used in practice in manufacturing hollow parts out of hard-to-deform materials such as titanium, aluminum, iron, magnesium, nickel-based and other advanced materials including intermetallic compounds and ceramics [1]. As compared with other known metal working techniques SPF enables one to produce complex shape parts by means of single operation using relatively cheap dies and tools.

Traditional superplastic forming techniques such as simple female forming (negative forming) and drape forming (forming by using male form blocks) are characterizing by occurrence of contact zones between tool and sheet. As a result, considerable non-uniform thickness distribution takes place in this case. At the same time, hollow parts may be manufacturing without die or by using the tools only at the final stage of forming. For example, British Aerospace is manufacturing pipe-lines and tanks by means of free forming of edge welded envelopes.

As shown in [2] the true strain at the spherical shell made of circular edge welded envelope is approximately two times lower in value as compared with that attained in similar shell produced by means of standard female forming, the time of forming being reduced to the half of the time of female forming under the same pressure. The application of free forming in manufacturing cylindrical shells also enables one to diminish considerably (approximately 3 times in value) the time of forming and the value of true strain obtained under the same value of pressure [3].
The principal feature of free forming is a considerable displacement of the equatorial zone towards the center so that the geometrical dimensions (diameter) of the shell produced turn out to be less as compared with the diameter of the initial edge welded envelope. When manufacturing spherical shells by means of free forming of circular edge welded envelope the ratio of the diameter of initial envelope to the diameter of the shell produced may attain the value up to 1.25 [4]. When forming rectangular edge welded envelopes the ratio of the width of the envelop to the diameter of cylindrical shell produced may attain the values up to $1.57[2,5]$.

Simplified analytical model of SPF of rectangular edge welded envelope has been developed in [5] which is based on principal assumptions of the thin shell theory and standard material model

$$
\sigma=K \xi^{m}, \text { or } \xi=C \sigma^{n},
$$

where $\sigma$ is the flow stress, $\xi$ is the strain rate, $K$ and $m$ are the rheological parameters to be determined from the results of mechanical experimentation; $n=1 / m, C=1 / K^{n}$. Finite element modeling of the process under study in [5] has been effected in terms of the boundary value problem in theory of creep, described in details elsewhere, see, e.g., $[6,7]$.

The objective of present study is to find our the peculiarities of the free forming of rectangular edge welded envelope by means of finite element consideration using ANSYS 10ED program.

Let us consider the schematic of free bulging of the rectangular edge welded envelope presented in Fig. 1. 


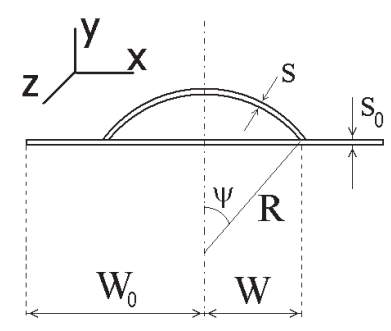

Fig. 1. Schematic of deforming a rectangular welded sheet envelope.

It is assumed further that the initial thickness of the sheet $s_{0}$ is much more less as compared with semi-width of the envelope $W$, which, in turn, is much more less as compared with the length of the $L_{0}: s_{0}<<W_{0}<<L_{0}$.

Since the envelope is contracting during forming its current semi-width $W$ is becoming less as compared with $W_{0}$. As far as the deformation along $\mathrm{Z}$-axis is concerned the following three situations are possible: a) plane stress state $\left.\left(\sigma_{z}=0, \varepsilon_{z} \neq 0\right) ; \mathrm{b}\right)$ plane strain state $\left.\left(\varepsilon_{z}=0, \sigma_{z} \neq 0\right) ; \mathrm{c}\right)$ deforming of the envelope of limited length when $\sigma_{z} \neq 0$ and $\varepsilon_{z} \neq 0$, the value of $\sigma_{z}$ being calculated from the equilibrium equations [5].

To generalize the material model (1) for the case of nonuniform stress state the proportionality of stress and stress rate deviators is assumed in further analysis as follows [1]:

$$
S_{i j}=\left(2 \sigma_{e} / 3 \xi_{e}\right) \xi_{i j}
$$

where $S_{i j}$ and $\xi_{i j}$ are the components of stress and strain rate deviators respectively, $\sigma_{e}$ is equivalent Mises stress and $\xi_{e}$ is equivalent strain rate:

$$
\sigma_{\mathrm{e}}=\sqrt{\frac{3}{2} S_{i j} S_{i j}}, \quad \xi_{\mathrm{e}}=\sqrt{\frac{2}{3} \xi_{\mathrm{ij}} \xi_{\mathrm{ij}}} .
$$

According to principal assumptions of the thin shell theory the stress state at the shell is determined by two non-zero components of stress: tangential, $\sigma_{t}$, and axial, $\sigma_{z}$. Correspondingly stress deviator has three non-zero components as follows:

$$
S_{11}=\left(2 \sigma_{t}-\sigma_{z}\right) / 3 ; \quad S_{22}=\left(2 \sigma_{z}-\sigma_{t}\right) / 3 ; \quad S_{33}=-\left(\sigma_{t}+\sigma_{z}\right) / 3 .
$$

Then, equivalent Mises stress is equal to

$$
o_{e}=\sqrt{\frac{3}{2} S_{i j} S_{i j}}=\sqrt{\sigma_{t}^{2}+\sigma_{z}^{2}-\sigma_{t} \sigma_{z}} \text {. }
$$

Strain rate tensor has, in general, three non-zero components: tangential, $\xi_{t}$, axial, $\xi_{z}$ and normal, $\xi_{n}$. From incompressibility it follows that $\xi_{t}+\xi_{z}+\xi_{n}=0$, and so strain rate tensor coincides with its deviator. Taking into account that $\xi_{n}=-\left(\xi_{t}+\xi_{z}\right)$ one has

$$
\begin{aligned}
& \xi_{e}=\sqrt{\frac{2}{3} \xi_{i j} \xi_{i j}}=\sqrt{\frac{2}{3}\left[\xi_{m}^{2}+\xi_{z}^{2}+\left(\xi_{m}+\xi_{z}\right)^{2}\right]}= \\
& =\frac{2}{\sqrt{3}} \sqrt{\xi_{m}^{2}+\xi_{z}^{2}+\xi_{m} \xi_{z}} .
\end{aligned}
$$

Strain tensor has also three non-zero components: $\varepsilon_{t}=\ln \left(R \psi / W_{0}\right)$, the values of $\varepsilon_{z}$ and $\varepsilon_{n}$ being dependable upon the kind of stress-strain state at the zone of deformation. Let us consider all possible three cases in turn.

For the case of plane stress state one has $\sigma_{z}=0$, and so $\sigma_{e}=\sigma_{m}$ and one can find from (4) and (2) that $\xi_{z}=\xi_{n}^{z}=-\xi_{m} / 2$, so that $\xi_{e}=\xi_{m}$. Principal strains in this case are as follows:

$$
\varepsilon_{t}=\ln \left(R \psi / W_{0}\right), \quad \varepsilon_{z}=\varepsilon_{n}=-\varepsilon_{t} / 2 .
$$

For the case of plane strain state $\xi_{z}=0$ and $\varepsilon_{z}=0$ and so one can find from (4) that $\sigma_{z}=\sigma_{t} / 2$ and $\sigma_{e}=(\sqrt{ } 3 / 2) \sigma_{t} ; \xi_{e}=(2 / \sqrt{ } 3) \xi_{t}$.
To consider the intermediate case let us project all acting forces to the axes of co-ordinates:

Axis Y: $p W=\sigma_{t} s \cdot$ siny;

Axis Z: $2 R \sigma_{z} \psi s=p R^{2}(\psi-\sin \psi \cos \psi)$.

From geometrical considerations it follows that

$$
R=W / \sin \psi
$$

Keeping in mind (8) one obtains

$$
\begin{gathered}
\sigma_{\mathrm{t}}=\frac{\mathrm{pR}}{\mathrm{s}}, \quad \sigma_{\mathrm{z}}=\frac{\mathrm{pR}}{2 \mathrm{~s}} \cdot \frac{\psi-\sin \psi \cos \psi}{\psi}, \\
\sigma_{\mathrm{e}}=\frac{\mathrm{pR}}{2 \mathrm{~s}} \cdot \sqrt{3+\left(\frac{\sin 2 \psi}{2 \psi}\right)^{2}} .
\end{gathered}
$$

From (9) it follows that at the very beginning of forming (when $\psi=0$ ) the following equality takes place: $\sigma_{e}=\sigma_{t}$ (similar to the case of plane stress state) while to the end of forming (with $\psi=\pi / 2)$ one has $\sigma_{e}=(\sqrt{3} / 2) \sigma_{t}$ (similar to the case of plane strain state). The conclusion is as follows: deforming of the envelope of limited length (when $\sigma_{z} \neq 0$ and $\varepsilon_{z} \neq 0$ ) can be considered as intermediate state between plane stress and plane strain. That is why the following two cases will be considered further in more details: plane stress $\left(\sigma_{z}=0\right)$ and plane strain $\left(\xi_{z}=0\right.$ and $\left.\varepsilon_{z}=0\right)$.

For the case of plane stress one has $\sigma_{z}=0, \quad \sigma_{e}=\sigma_{m} \quad$ and $\quad \xi_{e}=\xi_{m}, \quad \xi_{z}=\xi_{n}=-\xi_{m} / 2 \quad$ and so $\varepsilon_{t}=\ln \left(R \psi / W_{0}\right)=-2 \varepsilon_{n}=-2 \ln \left(s / s_{0}\right)=-2 \varepsilon_{z}=-2 \ln \left(L / L_{0}\right)$, where $L$ is current length of the envelope. Hence,

$$
\mathrm{s}=\mathrm{s}_{0} \sqrt{\frac{\mathrm{W}_{0}}{\mathrm{R} \psi}}=\mathrm{s}_{0} \sqrt{\frac{\mathrm{W}_{0}}{\mathrm{~W}} \cdot \frac{\sin \psi}{\psi}} \quad\left(\sigma_{\mathrm{z}}=0\right) .
$$

For the case of plane strain one has $\xi_{z}=0$ and $\varepsilon_{z}=0$, $\sigma_{e}=(\sqrt{3} / 2) \sigma_{t} ; \xi_{e}=(2 / \sqrt{ } 3) \xi_{t}$. From the incompressibility condition $\xi_{t}=-\xi_{n}$ and $\varepsilon_{t}=\ln \left(R \psi / W_{0}\right)=-\varepsilon_{n}=-\ln \left(s / s_{0}\right)$, so that

$$
\mathrm{s}=\mathrm{s}_{0} \frac{\mathrm{W}_{0}}{\mathrm{R} \psi}=\mathrm{s}_{0} \frac{\mathrm{W}_{0}}{\mathrm{~W}} \cdot \frac{\sin \psi}{\psi} \quad\left(\xi_{\mathrm{z}}=0 \text { and } \varepsilon_{\mathrm{z}}=0\right)
$$

From (10) and (11) it follows that semi-width of the envelop W may be considered as independent variable, the solutions for both of equations (10) and (11) being available for an arbitrary value of $W$. The following estimates can be derived then for both cases under consideration if one assumes $s=s_{0}$ :

$$
\begin{aligned}
& \left(W / W_{0}\right)_{\min }=\min [\sin \psi / \psi]=2 / \pi \approx 0,637, \\
& \left(W_{0} / W\right)_{\max }=\max [\psi / \sin \psi]=\pi / 2 \approx 1,57 .
\end{aligned}
$$

At the same time, the condition $s=s_{0}=$ constant means that $\xi_{n}=(1 / \mathrm{s})(\mathrm{d} s / \mathrm{d} t) \equiv 0$ so that что $\xi_{t} \equiv 0$. In this case, it is not possible to satisfy both of equilibrium equations (9) since the following consequences from (9) are valid in this case:

$$
\begin{gathered}
\sigma_{\mathrm{e}}=\sigma_{\mathrm{t}}=\frac{\mathrm{pR}}{\mathrm{s}}=\mathrm{K} \xi_{\mathrm{e}}^{\mathrm{m}}=\mathrm{K} \cdot\left(\frac{\dot{\mathrm{R}}}{\mathrm{R}}+\frac{\dot{\psi}}{\psi}\right)^{\mathrm{m}} \quad\left(\sigma_{\mathrm{z}}=0\right), \\
\sigma_{\mathrm{e}}=\frac{\sqrt{3}}{2} \sigma_{\mathrm{t}}=\frac{\sqrt{3}}{2} \cdot \frac{\mathrm{pR}}{\mathrm{s}}=\mathrm{K} \cdot\left[\frac{2}{\sqrt{3}} \cdot\left(\frac{\dot{\mathrm{R}}}{\mathrm{R}}+\frac{\dot{\psi}}{\psi}\right)\right]^{\mathrm{m}} \\
\left(\xi_{\mathrm{z}}=0 \text { and } \varepsilon_{\mathrm{z}}=0\right)
\end{gathered}
$$

In order to characterize the stress state at the zone of deformation more thoroughly finite element modeling is used in further analysis. For practical calculations the rectangular envelope consisting of two sheets of Russian alloy VT14 (Ti-4,2Al-2,7Mo-1,2V) of initial thickness of $s_{0}=0,8 \mathrm{~mm}$ with average grain size of about $1-2 \mu \mathrm{m}$ has been chosen. Rectangular sheets gave been welded along their common 
perimeter by means of contact welding. The width of the weld is equal to $b=5 \mathrm{~mm}$. Length of the envelope is equal to $500 \mathrm{~mm}$, width (taking into account the value of $b$ ) is equal to $48 \mathrm{~mm}$, so that $W_{0}=19 \mathrm{~mm}$. The feeding entry has been attached to the upright of installation to provide free forming of the shell and the assembly has been placed into the furnace. Superplastic forming is effected by argon pressure of $0.1 \mathrm{MPa}$ under constant temperature $870^{\circ} \mathrm{C}$. The pressure has been reduced to zero level when achieving the cylindrical shape of the shell.

Solid model of the edge welded envelope is shown in Fig. 2.

Symmetry conditions are applied on line 1-6 (UX=0) and line $2-3(U Y=0)$, pressure being applied on the line $1-2$. The rheological parameters of alloy VT14 have been assumed as follows: $K=100 \mathrm{MPa} \cdot \mathrm{s}^{m}, m=0,52$ [2]. Then one can find that $n=1 / m=1,923 ; C=1 / K^{n}=4,125 \cdot 10^{-16} \mathrm{~Pa}^{-n} \mathrm{~s}^{-1}$. These values have been introduced into the program ANSYS in solving the boundary value problem in the theory of creep for two different cases: plane stress $\left(\sigma_{z}=0\right)$ and plane strain $\left(\varepsilon_{z}=0\right)$.

Finite element mesh includes 480 elements PLANE82 (see Fig. 3), the option Plane strain being chosen for tha case when $\varepsilon_{z}=0$ and Plane stress for the case when $\sigma_{z}=0$.

For the sake of comparison, the time of forming has been chosen the same for both cases considered, the pressure being applied in accordance with the linear law: $p(t)=p_{\max } t / t_{\max }$, where $p_{\max }, t_{\max }$ are the parameters of the law. One can select the value of $p_{\max }$ in accordance with procedure suggested in [5] as follows

$$
\mathrm{p}_{\max }=\frac{\pi}{\sqrt{3}} \frac{\mathrm{s}_{0}}{\mathrm{~W}_{0}} \sigma_{\text {opt }} .
$$

The following result has been found for the envelope chosen: $p_{\max }=0.372 \mathrm{MPa}$. The time of forming can be estimated approximately from the following condition: $t=\varepsilon / \xi$, where $\varepsilon$ is estimate for strain, $\xi$ is estimate for strain rate. For the case when $\xi=10^{-3} \mathrm{~s}^{-1} \varepsilon=0.1$ the estimate for time of forming is equal to $100 \mathrm{~s}$.

The results of calculations are presented in Figs $4-7$. One can see that at the very beginning of the process (during the first $20 \mathrm{~s}$ ) the height of the envelop increases up to $\sim 12 \mathrm{~mm}$, the value of $\mathrm{W}$ being diminishing to approximately $13 \mathrm{~mm}$ (Fig. 4a).

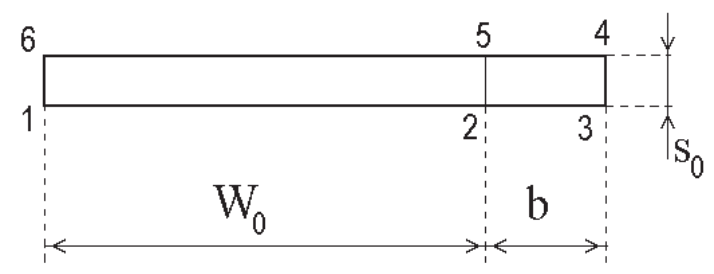

Fig. 2. Solid model.

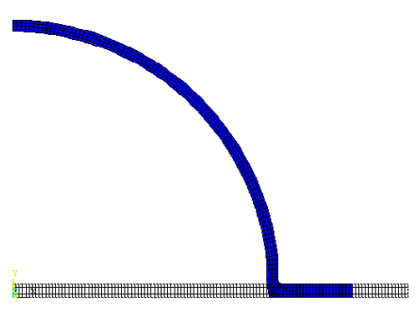

Fig. 3. Finite element mesh at the initial and final positions.
After the quick initial stage of deformation, the dome height is increasing much more slowly while the width of the envelope is increasing in value (Fig. 4b).

As one can see in Fig. 5b, the third principal creep strain attains the value of about $\varepsilon_{3}=-0.124$ for the case of plane stress and $\varepsilon_{3}=-0.152$ for the case of plane strain.

Experimentally it has been found $s_{\min } / s_{0}=0.87$ [5]. From this it follows that $\varepsilon_{3 \exp }=\ln \left(s_{\min } / s_{0}\right)=-0.139$. The second principal strain turns out to be equal to $\varepsilon_{2}=-0.114$ at $t=t_{\max }$ (for the case of plane stress). Experimentally it has been found that the envelope of initial length $500 \mathrm{~mm}$ has been compressed to the final length of about $450 \mathrm{~mm}$ [5], so that $\varepsilon_{\text {2exp }} \approx \ln (450 / 500)=-0.105$.

As seen in Fig. 6, principal stresses $\sigma_{1}$ and $\sigma_{2}$ are negligible in value within first $\sim 10 \mathrm{~s}$ of forming however, the dome height is increasing while width is diminishing (see Fig. 4). Besides, the values of principal creep strains are also negligible in this period of forming (Fig. 5). From this it follows that an elastic bending of the envelope is occurred at the very initial stage of forming. The dependencies of equivalent Mises stress shown in Fig. 7 also confirm such conclusion.

\section{Summary}

Finite element consideration of the free superplastic forming of rectangular edge welded envelope has been fulfilled in this study. It is shown that the forming of the envelope is characterizing by the following three stages. At first stage of forming an elastic bending of the envelope takes place when the dome height is sharply increasing while the width is diminishing in value. Second stage of forming corresponds to the stable superplastic flow when the dome height and width of the shell are changing insignificantly. During the third stage of forming the increase in the dome height is accomplished by increase in the width of the shell.

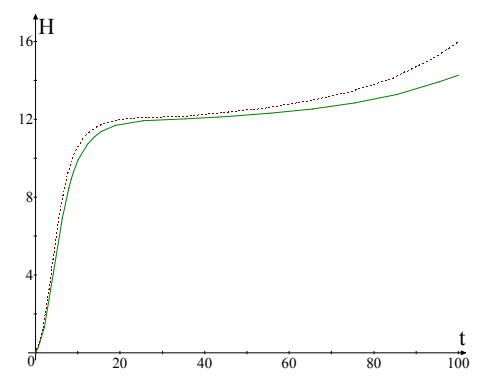

(a)

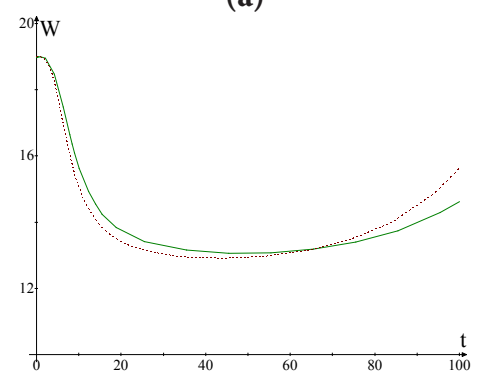

(b)

Fig. 4. Time dependencies of the dome height, $H, \mathrm{~mm}$ (a) and the half-width of the envelope, $W, \mathrm{~mm}(\mathrm{~b})$, calculated for the plane strain state (solid lines) and the plane stress state (dashed line) by means finite element method. 


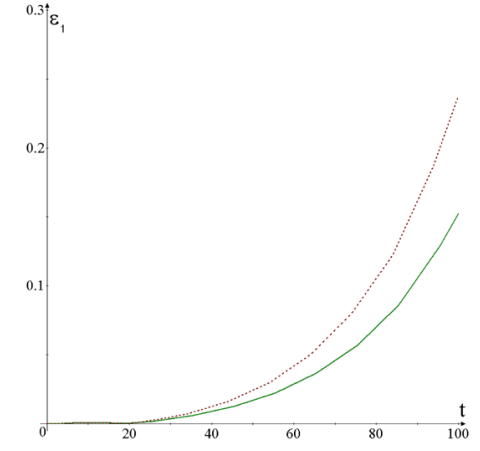

(a)

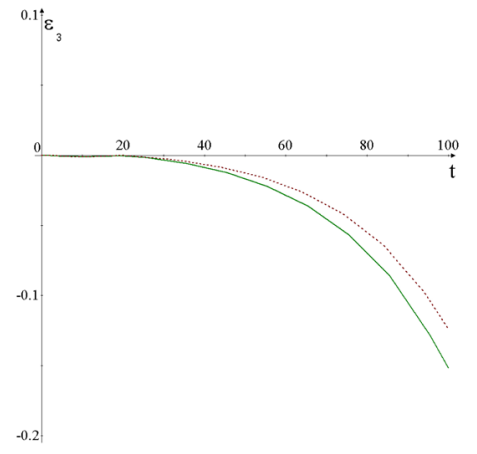

(b)

Fig. 5. Time dependencies of the first principal creep strain $\varepsilon_{1}(\mathrm{a})$ and the third principal creep strain $\varepsilon_{3}(\mathrm{~b})$, calculated for the plane strain state (solid lines) and the plane stress state (dashed line).

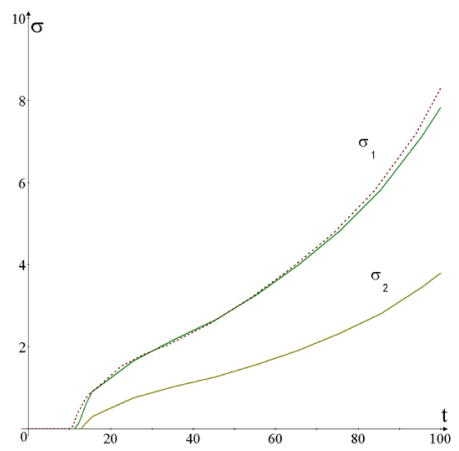

Fig. 6. Time dependencies of the first and second principal stresses $\sigma$ $\sigma_{2}, \mathrm{MPa}$, with, calculated for the plane strain state (solid lines) and the plane stress state (dashed line).

\section{References}

1. O.M. Smirnov. Superplastic metal working techniques. Moscow: Mashinostroenie (1979) 184 p. (in Russian) [О.М. Смирнов Обработка металлов давлением в состоянии сверхпластичности. М.: Машиностроение, (1979) 184 c.].

2. T.M. Zagirov, A.A.Kruglov, F.U. Enikeev. Russian Journal of Non-Ferrous Metals 52(2), 175 (2011).

3. T.M. Zagirov, A.A.Kruglov, F.U. Enikeev. Kuznechnoshtampovochnoe proizvodtvo 4, 31 (2010) (in Russian) [Загиров Т.М., Круглов А.А., Еникеев Ф.У. Кузнечноштамповочное производство 4, 31 (2010)].

4. A.A. Kruglov, F.U. Enikeev, R.Ya. Lutfullin. Materials Science and Engineering A 323, 416 (2002).

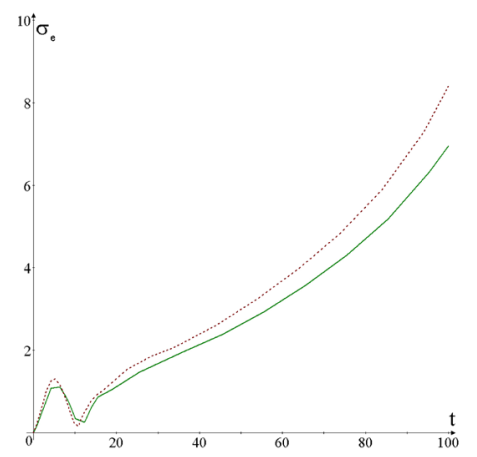

Fig. 7. Time dependencies of the equivalent Mises stress, $\sigma, \mathrm{MPa}$, calculated for the plane strain state (solid lines) and the plane stress state (dashed line).

5. A.A.Kruglov, F.U. Enikeev. Mekhanika deformirovannogo tverdogo tela i obrabotki metallov davleniem. Tula, TulGu. 2, 41 (2005) (in Russian) [А.А. Круглов, Ф.У. Еникеев. Известия Тульского государственного университета, Механика деформируемого твердого тела и обработка металлов давлением. Тула: ТулГУ. 2, 41 (2005)].

6. F.U. Enikeev. Izvestiya vuzov. Tcvetnaya metalurgiya 1, 45 (2008) (in Russian) [Ф.У. Еникеев. Известия вузов. Цв. металлургия 1, 43 (2008)].

7. A.Yu. Samoilova, V.R. Ganieva, F.U. Enikeev, A.A. Kruglov. Letters on Materials 3(3), 252 (2013) (in Russian) [А.Ю. Самойлова, В.Р. Ганиева, Ф.У. Еникеев, А.А. Круглов. Письма о материалах 3(3), 252 (2013)]. 